\title{
MOTIVAÇÃO DA GESTÃO PARA IMPLEMENTAÇÃO DA AVALIAÇÃO INSTITUCIONAL NA EDUCAÇÃO PROFISSIONAL E TECNOLÓGICA
}

\begin{abstract}
Heula Tíssia Alves Moreira de Almeida ${ }^{1}$
Simone Braz Ferreira Gontijo ${ }^{2}$

Resumo

Paulo Jorge de Castro Coelho Dias ${ }^{3}$

Este artigo objetivou identificar a percepção da equipe gestora de uma instituição federal de educação profissional e tecnológica quanto à avaliação institucional e as ações provenientes dela, na perspectiva da gestão democrática. A pesquisa foi realizada um campus selecionado por apresentar o processo de avaliação institucional interna como uma prática constante para o direcionamento da ação gestora e caracterizou-se como estudo de caso. Foram realizadas entrevistas com o corpo diretivo e a administradora do campus. Os resultados apontam que para a gestão a avaliação é um elemento democrático, mas é preciso maturidade para lidar com os resultados da avaliação institucional.
\end{abstract}

Palavras-chave: Gestão democrática; Instrumentos de avaliação; Participação.

\section{MOTIVATION OF MANAGEMENT TEAM FOR IMPLEMENTING INSTITUTIONAL ASSESSMENT IN PROFESSIONAL AND TECHNOLOGY EDUCATION}

\begin{abstract}
The aim of this article was to identify the perception of a management team in a Federal Institution of Professional and Technology Education regarding institutional assessment and the resulting actions, in the context of democratic management. The campus was selected for the research because it consistently holds the process of internal institutional assessment in order to guide the management team actions. It is a case study. We held interviews with the body of managers and the administrator of the campus. Results show that managers see the assessment as a democratic element, but they acknowledge it takes professional maturity to handle the results of the institutional assessment.
\end{abstract}

Key-words: Democratic management; Assessment instruments; Participation.

\footnotetext{
${ }^{1}$ Instituto Federal de Brasília, Técnica em Assuntos Educacionais, mestra em Administração Educacional pelo Instituto Politécnico de Santarém. Membro do grupo de pesquisas Gefor. Endereço: CSB 10 Lote 2/3 Apartamento 1101 Bl A - Taguatinga Sul, Brasília - DF. Telefone: (61) 98596-9828, E-mail: heula.moreira@ gmail.com

${ }^{2}$ Instituto Federal de Brasília, Professora de Educação Profissional e Tecnológica, doutora em Educação pela Universidade de Brasília. Líder do grupo de estudos e pesquisas Gefor. Endereço: Rua 28 Norte Lote 2 Ap.1301 Águas Claras, Brasília - DF. Telefone: (61) 99228-5489. E-mail: simone.gontijo@ifb.edu.br

${ }^{3}$ Escola Superior de Educação - Instituto Politécnico de Santarém, doutor em Sociologia da Educação pela Universidade Nova de Lisboa. Chefe do departamento de Ciências Sociais. Pesquisador do Centro de Investigação e Estudos em Sociologia do Instituto Universitário de Lisboa. Endereço: Complexo Andaluz, Apartado 131 Santarém - Portugal. Telefone: 351243309 180. E-mail: paulo.dias@ese.ipsantarem.pt
} 


\section{INTRODUÇÃO}

Este artigo trata da avaliação institucional no contexto das práticas de gestão democrática na educação profissional e tecnológica e tem como objetivo identificar a percepção da equipe gestora de uma instituição federal de educação profissional e tecnológica quanto à implantação da avaliação institucional e as ações provenientes dela, numa perspectiva de gestão democrática.

Em função da amplitude do tema, neste trabalho apresentar-se-á parte dos dados da dissertação de mestrado que teve como objetivo analisar as práticas avaliativas institucionais desenvolvidas em um campus da Rede Federal de Educação Profissional e Tecnológica, buscando compreender as motivações e ações realizadas pelo corpo gestor, numa perspectiva de gestão democrática e participativa, voltadas a avaliação institucional interna. (FREITAS; SORDI; MALAVASSI, 2014).

A avaliação é um processo intrínseco à instituição, visto que interfere e produz efeitos sobre o seu funcionamento presente e futuro visando o aperfeiçoamento do funcionamento e a melhoria dos resultados educacionais (BELLONI, 1999). E a escolha desse tema se deu em função de sua relevância no contexto gestão democrática, uma vez que a avaliação institucional, em especial a interna, é um instrumento potencializador da participação dos atores escolares na gestão possibilitando a reflexão acerca dos caminhos mais adequados às práticas pedagógico-administrativas, de forma a valorizar a participação daqueles que interagem no ambiente educacional, direcionando e redirecionando as suas ações da gestão.

A avaliação institucional escolar pode se caracterizar como uma estratégia de prospecção, construção de conhecimento e acompanhamento do trabalho realizado, em seus desdobramentos e detalhes, de modo a permitir a tomada de decisões apoiada objetivamente, bem como o planejamento e a organização do trabalho pedagógico (LUCK, 2012). A motivação dos gestores se mostra imprescindível para que o processo de avaliação institucional se torne presente no contexto escolar, complementando ações de uma gestão aberta ao diálogo, que se propõe a avaliar suas ações buscando efetivas melhorias. 


\section{REFERENCIAL TEÓRICO}

A gestão escolar traz consigo complexidades, pois um dos objetivos primordiais da escola é formar cidadãos e, para alcançá-lo ela conta com seus profissionais que devem ser envolvidos em prol dessa formação numa perspectiva de gestão participativa. Para melhor direcionar os distintos momentos e dilemas da prática educativa, pode-se contar com a avaliação institucional que poderá apontar fragilidades e potencialidades, favorecendo o planejamento e as ações gestoras.

Nesse trabalho, dois conceitos são fundamentais - avaliação institucional, gestão democrática e motivação. O Quadro 1 sintetiza esses conceitos:

\section{Quadro 1 - Conceitos fundamentais}
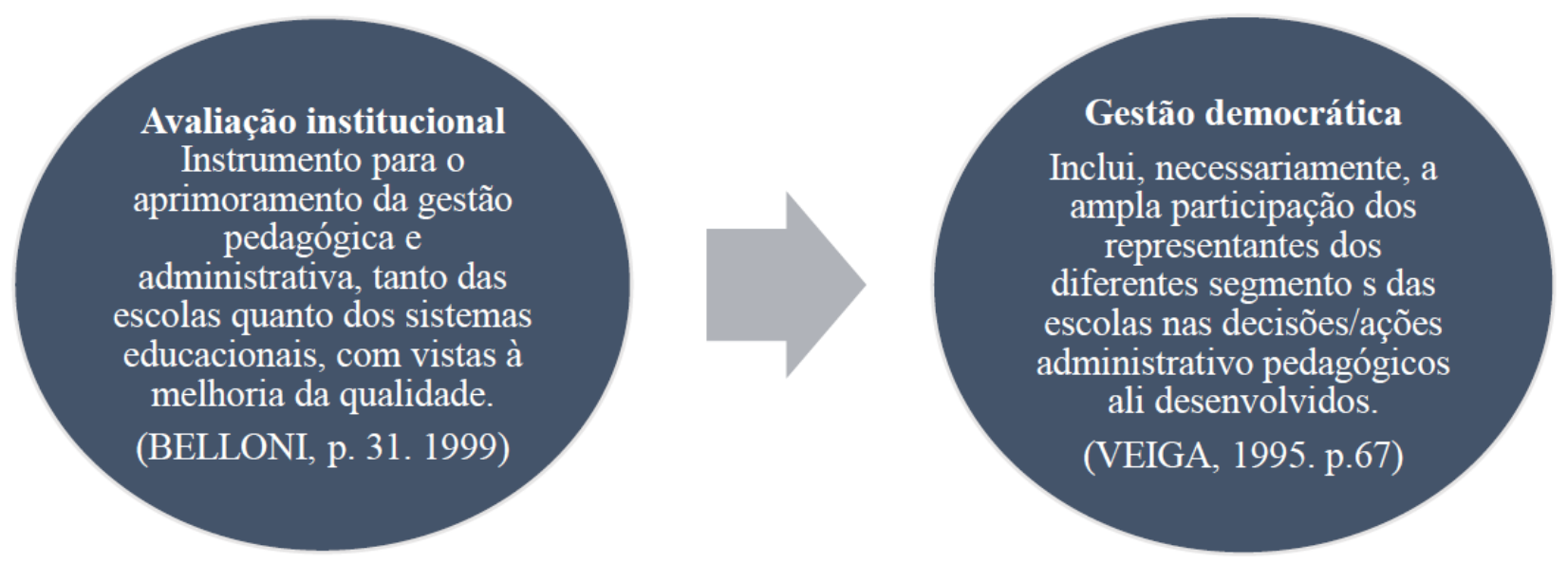

Fonte: Elaborado pela pesquisadora

A avaliação institucional da escola se mostra um processo que envolve todos os seus atores, com vistas a debater possibilidades de aprimoramento de sua ação, partindo das dificuldades concretas vivenciadas por ela. Constitui-se um processo integrado e múltiplo, no qual cada ação avaliativa possui um protagonista, sendo a avaliação institucional interna à escola, já que a avaliação em larga escala é externa e a avaliação da aprendizagem fica a cargo do professor (FREITAS et al, 2014).

Souza (1995) destaca que a avaliação institucional se constitui em um processo de busca de compreensão da realidade escolar, com finalidade de subsidiar as decisões quanto ao direcionamento das intervenções, visando ao aprimoramento do trabalho escolar. Dessa forma, envolve a descrição, a interpretação e o julgamento das ações desenvolvidas, resultando na 


\section{dAEPE|}

definição de prioridades a serem implementadas e direções a serem seguidas, tendo como referências os princípios e as finalidades estabelecidos no projeto pedagógico da escola, ao mesmo tempo em que subsidia a sua própria redefinição.

Por ser um processo em que se busca a compreensão da realidade escolar, deve ser vivenciado por todos que integram o espaço educativo, cabendo aos gestores promover e manter espaços de participação efetiva nos quais as ações da escola sejam avaliadas, tendo em vista a "relação entre o que existe e o que é esperado, entre um comportamento e um comportamento alvo, relação entre a realidade e um modelo ideal” (HADJI, 1994 p. 30).

A participação constitui-se numa forma significativa de promover a aproximação entre os membros da escola, visto que está centrada na busca de formas democráticas de promover a gestão. A promoção da participação pressupõe a interação entre direitos e deveres, marcados pela responsabilidade social e valores compartilhados e o esforço conjunto para a realização de objetivos educacionais (LUCK, 2008).

Neste sentido, "nas organizações a avaliação é fundamental em termos de gestão. Particularmente importante na estruturação das relações de trabalho, a avaliação é também um instrumento de controle e legitimação organizacional" (AFONSO, 2005, p. 18).

A avaliação institucional numa dimensão da gestão escolar, não é um fim em si mesma, uma vez que se justifica na medida em que colabora direta e efetivamente para a melhoria da capacidade da escola em promover seus objetivos educacionais por meio de uma gestão efetiva e associada ao planejamento e ao monitoramento, a serviço da responsabilidade social da escola (LUCK, 2012).

Com a avaliação institucional o que se espera é que o coletivo da escola localize seus problemas, suas contradições; promova momentos reflexivos sobre eles e estruture situações de melhoria a serem solicitadas ao poder público e ao mesmo tempo se comprometa com elas (FREITAS et al, 2014).

Para estruturar uma avaliação institucional com vistas ao aperfeiçoamento de práticas pedagógicas e administrativas, a equipe gestora precisa estar motivada a superar as limitações e dificuldades oriundas do processo, adversidades que são próprias de uma gestão democrática que se fortalece pela escuta, pelo debate, pelo convencimento.

A escola que passa por um processo avaliativo participativo tem condições de construir sua identidade, encontrar uma dinâmica própria. Aprende-se muito com esse processo, mas o 
que fica de mais importante é a vivência de um caminhar reflexivo, democrático, formativo. Todos crescem. Os dados coletados mudam, mas a vivência marca a vida das pessoas, renovando expectativas e compromissos com um trabalho qualitativo satisfatório tanto para a comunidade escolar quanto para a sociedade. Avaliação institucional é, portanto, um processo complexo. Ela precisa ser construída por cada escola. É o desafio de uma longa caminhada possível e necessária (FERNANDES, 2002).

\section{METODOLOGIA}

A pesquisa foi orientada pela abordagem qualitativa e caracterizou-se como estudo de caso. Indica-se que a pesquisa tem caráter qualitativo quando "tem como propósito identificar fatores que determinam ou contribuem para a ocorrência de fenômenos, convocando, abertamente, a subjetividade dos atores envolvidos sem uma preocupação de quantificação". (GIL, 2010, p. 28). Portanto, essa abordagem se adequa aos objetivos da pesquisa.

A pesquisa foi realizada um campus da Rede Federal de Ensino selecionado por apresentar o processo de avaliação institucional interna como uma prática constante para o direcionamento da ação gestora. O campus atende a cerca de 900 estudantes em cursos técnicos (subsequente e integrado); licenciatura; Formação Inicial e Continuada e atividades de extensão. O quadro de servidores é composto por 64 professores, 38 técnicos e 10 servidores terceirizados nas áreas de recepção, vigilância e limpeza.

Os interlocutores da pesquisa foram o corpo diretivo e a administradora da instituição. Os diretores foram entrevistados para que se obtivesse uma visão global do processo de avaliação institucional do campus; bem como as considerações acerca das práticas avaliativas. $\mathrm{O}$ roteiro da entrevista semiestruturado para os diretores foi composto por doze questões e o roteiro da entrevista com a administradora teve oito questões.

Os dados coletados foram apresentados sem distinguir a fala dos interlocutores por seus cargos a fim de resguardar a identidade de cada um deles e, também, porque a pesquisa visou identificar a percepção do grupo gestor. Os dados obtidos foram tratados mediante análise de conteúdo (BARDIN, 2016). 


\section{DISCUSSÃO DOS RESULTADOS}

\section{Motivação dos gestores para a construção do processo de Avaliação Institucional}

Para Belloni (1999, p. 40) a avaliação institucional é um "processo sistemático de busca de subsídios para melhoria e aperfeiçoamento da qualidade da instituição". Em relação a isso, pode-se inferir que os gestores percebem essa avaliação como uma forma de conhecer melhor e avaliar a instituição como um todo, verificando aspectos a serem melhorados já que possibilita um feedback das práticas de gestão.

[...] a gente consegue ter um feedback e eles se sentem pertencidos a esse processo de construção.

Vejo que a avaliação é importante para que você aperfeiçoe algo que está "deixando a desejar", e é muito intuitivo aplicar isso para a gestão. Então, eu preciso de uma avaliação para verificar onde esses processos, fluxos, setores, e até mesmo os servidores que estão deixando a desejar por qualquer motivo que seja e a avaliação vai dizer isso; a partir daí a gente poder aperfeiçoar.

[...] na medida em que você não avalia você não consegue ter dimensão se o que você está fazendo está no caminho certo. Então, eu acho que não é possível se pensar em uma gestão que se propõe democrática sem avaliar se os resultados do que a gestão está fazendo, ou seja, a ação tem um efeito naquelas pessoas que estão subordinadas aquelas ações.

A pesquisa indicou que o principal responsável pela implementação da avaliação institucional no campus foi o diretor geral. Esse, por sua vez, apresentou interesse em ter um retorno das ações realizadas pela gestão, buscando verificar se as expectativas do público atendido estavam sendo alcançadas, promovendo a gestão do campus numa perspectiva democrática. Essa afirmativa é corroborada nas seguintes falas:

O que mais motivou a implantação da avaliação do corpo diretor foi a filosofia de trabalho do diretor geral.

Quando assumi a Diretoria já existia essa cultura por parte do gestor máximo, no caso, o diretor geral, então, quando assumi ele já tinha essa visão, e aí, na verdade, eu só ajudo a operacionalizar.

Eu sempre compreendi a gestão como um ciclo que ele envolve a preparação, a execução e a medição dos resultados, que aí seria um monitoramento e uma avaliação. Então, isso já veio muito claro em minha cabeça, quando assumi, que a gente teria que criar um processo de avaliação... Então, a motivação veio disso, desse desejo muito forte de dar uma satisfação à sociedade, de dar uma satisfação à comunidade interna e de saber se o que eu propunha estava 


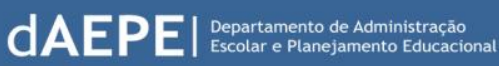

\section{ISSN 2359-82}

tendo reflexo que eu imaginava que teria. Então, essa paz interior de saber que as pessoas têm o direito de gostar ou não do seu gestor e não gostando, por conta da perspectiva de uma gestão democrática, eles têm o direito de trocar. Então, essa é a grande motivação.

Portanto, para esse grupo gestor é fundamental ter as ações avaliadas pelo público da instituição, oportunizando o diálogo, a discussão coletiva que compõe uma gestão democrática.

\section{Ações voltadas a Avaliação Institucional}

As ações voltadas a realização da avaliação institucional no campus estão pautadas em dois níveis: avaliação dos gestores pelos servidores e avaliação dos setores/docentes pelos estudantes.

Os gestores afirmaram que dentre os instrumentos utilizados pelo campus na avaliação institucional os principais são as reuniões e formulários de avaliação das direções, a autoavaliação dos gestores, o formulário de avaliação dos docentes e dos setores de atendimento.

A avaliação dos gestores pelos servidores é composta pela aplicação de um questionário on-line enviado por e-mail aos servidores semestralmente e por uma reunião presencial avaliativa realizada anualmente. A avaliação dos professores acontece semestralmente, por meio da aplicação de questionários. Em 2017, foi implementada a avaliação dos setores de atendimento aos estudantes, também realizada por meio de questionário em formulário on-line.

A “a autoavaliação é o momento em que os sujeitos produzem uma reflexão coletiva, uma diagnose a respeito do conjunto de atividades institucionais, apresentando subsídios para uma tomada de consciência” (QUEIROZ, 2011. p. 87). Se a autoavaliação institucional traz uma reflexão coletiva subsidiando a tomada de consciência, logo, a autoavaliação dos gestores favorece o reconhecimento de suas limitações, para que ela seja efetiva, os gestores precisam esvaziar-se de seus preconceitos, buscando formas de sanar as dificuldades percebidas. Em relação à autoavaliação destaca-se que, apesar de mencionada por alguns gestores, não houve continuidade dessa prática:

Aplicamos a autoavaliação para os gestores somente no primeiro semestre de 2016 e depois suspendemos com o objetivo de melhorarmos o instrumento para ter mais utilidade e não aplicarmos somente por obrigação. Nunca mais houve preocupação ou demandas por isso.

Pode-se considerar lamantável o abandono da prática de autoaavaliação, uma vez que na avaliação institucional "a autoavaliação é o momento em que os sujeitos produzem uma 


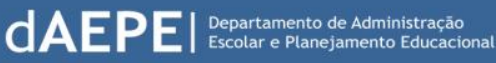

\section{ISSN 2359-82}

reflexão coletiva, uma diagnose a respeito do conjunto de atividades institucionais, apresentando subsídios para uma tomada de consciência" (Queiroz, 2011. p. 87). Se a autoavaliação institucional traz uma reflexão coletiva subsidiando a tomada de consciência, logo, a autoavaliação dos gestores favorece o reconhecimento de suas limitações, para que ela seja efetiva, os gestores precisam esvaziar-se de seus preconceitos, buscando formas de sanar as dificuldades percebidas.

O campus conta ainda com um formulário disponível na recepção do campus destinado à comunidade escolar com a finalidade de registrar sugestões, críticas, elogios; com um cronograma de visita às salas de aula por parte da direção; com o serviço de ouvidoria institucional externa ao campus e outros mecanismos que auxiliam no processo de avaliação.

Tem o formulário "Deixe aqui seu recado". Temos a ouvidoria interna que é uma fonte de avaliação para nós que sempre contribui. Em certo sentido a auditoria interna também contribui com o processo de avaliação, porque eles auditam e sabemos como estamos. E isso que eu falei antes, de ir às salas, completa o processo.

A avaliação institucional gera ansiedades em muitos avaliadores e, principalmente, nos avaliados. Como esse tema sempre foi associado à punição, ela ainda é vista, em muitos ambientes, como um processo ameaçador, como as "provas" de desempenho (GADOTTI, 2010).

Essa situação é materializada em relação à reunião presencial avaliativa, pois esse instrumento expõe os diretores tornando o momento improdutivo.

As pessoas tinham voz, apenas para criticar e, talvez, esse não seja o grande motivo que leve a esse tipo de situação. Eu acho que o caminho é pelo google drive com a ideia do anonimato, isso aí eu, eu resguardo como importante, mas essa reunião dos servidores da ponta pra avaliar perdeu um pouco o sentido na medida em que a crítica foi muito direcionada e muito por questões que nem sempre envolviam só profissionalismo dos gestores.

Em uma analogia a avaliação de desempenho que busca favorecer o desenvolvimento do profissional, um dos pontos fracos é quando o avaliado se sente injustiçado com o processo ou quando a avaliação provoca reações negativas (CHIAVENATO, 2004). A equipe de gestão não está ilesa a esses sentimentos evocados pela avaliação. Palavras como insegurança e preocupação fizeram parte dos depoimentos.

O diretor afirma que, quanto à avaliação: 
Eu me senti um tanto quanto afetado, negativamente. Eu diria, porque a gente se sente pressionado... Então eu tive alguma dificuldade em aceitar as críticas.

A primeira sensação... é de ficar com medo, é aquela insegurança... O meu primeiro sentimento é de preocupação com o que os outros estão pensando. É de receio em ser mal avaliada até porque eu me dedico tanto ao meu trabalho e de repente a possibilidade de ser mal avaliada me traz uma certa ansiedade... Mas na hora que se racionaliza o negócio é aquela coisa, se eu tiver realmente fazendo o meu trabalho isso será refletido na avaliação.

Também é destacada a personificação da avaliação, isto é, não se avalia o trabalho, mas a pessoa:

Detesto aquilo! Eu vou ser franca... É expor! Parece que as pessoas estão num circo sendo apedrejadas ou expostas. Não acho aquilo produtivo... Detesto aquilo! Não gosto.

Chiavenato (2014) corrobora que toda pessoa necessita receber um feedback em relação ao seu desempenho para saber como está realizando suas funções e a avaliação realizada no ambiente escolar deve propor a reflexão das ações, o crescimento profissional, a construção de um ambiente educacional melhor. Porém, é preciso cuidar da forma como é dado esse feedback.

Um dos requisitos da avaliação de desempenho é enfatizar o desempenho do colaborador e não se concentrar em uma análise subjetiva de hábitos pessoais. A avaliação deve proporcionar benefícios para a organização e para as pessoas. Essa percepção quanto a injustiça e avaliação pessoal é compartilhada por outros gestores:

Emocionalmente é um desafio permanente a toda avaliação que chega, porque ninguém gosta de ser, de certa forma se sentir injustiçado. Então, algumas críticas a gente percebe a intenção de ajudar, de sugerir e algumas críticas a gente percebe a intenção de machucar, de ir direto no pessoal. Emocionalmente mexe com a gente.

Na hora de tratar os dados, ainda são muito imaturos e vulneráveis, muitas vezes levando para o lado pessoal, tentando adivinhar quem foi que escreveu, ou justificando que há pessoas contrárias à gestão e que não perdem a oportunidade de demonstrar isso na avaliação. Realmente existem essas pessoas, mas também há aquelas que falam, que participam não somente para fazer uma perseguição, mas buscando a melhoria do todo.

Portanto, alguns sentimentos dificultam que o processo de avaliação institucional cumpra seus objetivos de autoconhecimento e a orientação do processo de tomada de decisão. Sobre isso um dos entrevistados afirma:

Quem mais defende o instrumento de avaliação é o que melhor aceita os resultados da avaliação. Já os outros gestores ainda não tinham a capacidade de considerar a avaliação como uma oportunidade de melhoria e acabavam levando para o lado pessoal e se sentindo 
ameaçados com a avaliação. Eram os que menos tinham capacidade de enxergar as potencialidades por trás das críticas. Entretanto, mesmo não tendo uma boa receptividade em relação aos resultados, nunca se posicionaram contrários à avaliação, nem resistentes. Concordavam em serem avaliados. Contudo, a imaturidade de lidar com os resultados se revelavam de forma prática nos encaminhamentos e no direcionamento das próprias ações.

A avaliação de desempenho está mais orientada para o planejamento do desempenho futuro do que para o julgamento do desempenho passado (CHIAVENATO, 2014). É fundamental que as pessoas recebam feedback do seu trabalho para que não caminhem às cegas. Também a organização precisa saber como as pessoas desempenham as suas atividades para ter uma ideia de suas potencialidades. Nesse aspecto se torna necessário que os gestores compreendam a avaliação como um momento de reflexão com vistas à superação de limitações percebidas.

Quanto as ações voltadas à avaliação institucional destacam-se algumas limitações que precisam ser consideradas para a efetividade do processo. É importante que exista uma reflexão contínua para que a metodologia de avaliação institucional seja aprimorada para melhor atender os objetivos que se propõe.

Em relação ao aperfeiçoamento da metodologia de avaliação institucional o diretor afirma:

A metodologia foi sendo aprimorada a cada avaliação, observando as colocações dos participantes tanto no próprio instrumento, como nas apresentações das avaliações e outras percepções dos gestores.

Dentre os instrumentos em processo de análise no campus podemos destacar:

Estamos analisando junto à equipe de planejamento porque essa reunião presencial vem chegando para a gente por meio da ata apontando os problemas, mas não apontando se aquilo é visão do grupo ou a visão de uma, duas, três pessoas. Então, a gente começou a ficar sem parâmetro. Às vezes a maioria do grupo está concordando, mas não está participando. Então, começou a nos preocupar, estamos debatendo isso com a área de planejamento para avaliar isso melhor. Reunião de avaliação presencial.

Sei que o instrumento também pode melhorar, porque algumas perguntas na hora que a gente vai fazer a análise dos resultados é que a gente vai ver, que a gente percebe que a pergunta está mal formulada ou que as opções não estão adequadas. Pesquisa on-line.

Acho que talvez a gente tenha que repensar todo o modelo, porque a gente ainda não tem uma ferramenta que possa nos dar um resultado mais fidedigno. 


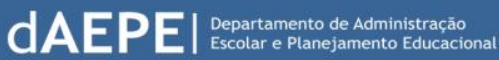

É perceptível a preocupação o aprimoramento das práticas avaliativas o que demonstra a valorização do processo e o interesse de incorporar novos instrumentos. É necessário, portanto, que os instrumentos sejam reformulados de forma coletiva sempre que necessário tendo em vista o alcance dos objetivos e a legitimidade da ação avaliativa.

Nesse aspecto, para que uma instituição desenvolva uma cultura de avaliação é preciso que seja uma ação contínua, permanente e democrática, rompendo as resistências e favorecendo a participação da comunidade acadêmica (QUEIROZ, 2011).

A preocupação dos gestores em relação às críticas, em relação ao lado pessoal e à participação verbal reduzida dos que estão na reunião de avaliação traz ponderações quanto à metodologia utilizada. A avaliação de desempenho tem como principal finalidade o reconhecimento do desempenho individual do colaborador, com vista a aprimorá-lo e de forma que melhores resultados sejam alcançados pela organização (CHIAVENATO, 2004). No caso da avaliação dos gestores é preciso que os servidores estejam atentos às ações da gestão que podem ser aprimoradas por meio das sugestões que são recebidas, com vistas ao aperfeiçoamento da gestão e consequentemente da instituição.

\section{Ações advindas da Avaliação Institucional}

A avaliação institucional é um processo intrínseco à instituição, uma vez que interfere e produz efeitos sobre o seu funcionamento presente e futuro visando o aperfeiçoamento do funcionamento e a melhoria dos resultados educacionais (BELLONI, 1999).

Percebe-se, pela fala dos gestores que eles compreendem a avaliação como algo amplo. Indicam que a instituição está num momento inicial da avaliação institucional e que precisam ampliar as práticas e reformular instrumentos para atingir seus objetivos. Apesar de um dos gestores considerar que os objetivos dessa avaliação têm sido alcançados, há questões a serem melhoradas.

Belloni (1999, p. 42) afirma que "é preciso que as pessoas assumam a avaliação como parte de seu cotidiano [...] precisamos criar uma cultura institucional de que a avaliação faz parte da nossa rotina, constituindo-se em uma ação regular da instituição".

É interessante perceber que, conforme colocado por um gestor, já existe um ganho quanto à legitimidade da avaliação institucional no contexto do campus estudado, 
depreendendo-se que a avaliação faz parte da rotina institucional, principalmente pela frequência com que as avaliações acontecem.

Quanto à utilização da avaliação como direcionamento das ações da gestão algumas práticas relevantes foram apresentadas, tais como o feedback do trabalho realizado nas reuniões setoriais ${ }^{4}$, ação que resultou numa otimização do tempo; no acompanhamento e direcionamento pedagógico do trabalho docente; em melhorias dos setores de atendimento ao público interno e externo.

Entre o próprio grupo de gestores a avaliação institucional também gerou aprimoramento do trabalho. O diretor afirma que foram muitas contribuições e que ficaria difícil de listar, mas como relevantes citou o diálogo entre gestores para analisar os resultados da avaliação, democratização do processo de escolha de coordenadores, suporte pedagógico para os docentes, provisionamento dos setores, direcionamento dos perfis dos gestores diretores intermediários, feedback aos servidores dos resultados da avaliação:

O método de indicação de pessoas para assumir coordenações. Conversar com os gestores, até no caso dos dois diretores, eu faço uma escolha, então, eu uso o que a avaliação estava criticando no gestor anterior e tento ver qual perfil que eu preciso para me assessorar nessa direção intermediária. Na avaliação que os alunos fazem dos professores quando dá um resultado abaixo de um determinado o patamar nós conversamos com o professor, chamamos e oferecemos suporte pedagógico. Em relação aos formulários on-line, eu dou um retorno para a comunidade a partir das últimas avaliações.

Apesar dos gestores considerarem que a avaliação proporciona um direcionamento das ações, caso os feedbacks recebidos não sejam efetivamente considerados, a avaliação ficará comprometida.

Com o passar das avaliações, alguns participantes demonstraram falta de credibilidade e de confiança de que são ouvidos ou de que os temas apontados nas avaliações são tratados de forma direcionada e planejada. Portanto, as pessoas valorizavam o instrumento e contribuíam para melhorias e não era exatamente o instrumento de pesquisa o problema, mas o tratamento dos dados que perdiam a qualidade e atenção necessários.

Assim, é fundamental que a equipe gestora busque aprimorar o processo a fim de evitar constrangimentos, prejudicar o andamento do processo de avaliação ou mesmo contradizer a gestão democrática a que se propõe. Ainda nesse aspecto, é imprescindível que o tratamento dos dados seja aprimorado, de forma a valorizar a participação, dar legitimidade e credibilidade ao

\footnotetext{
${ }^{4}$ Reuniões realizadas pelo gestor com servidores de determinado setor, exclusivamente.
} 
processo. Nessa perspectiva, Libâneo et al. (2012, p. 454) afirmam que: "a participação, o diálogo, a discussão coletiva, a autonomia são práticas indispensáveis da gestão democrática”.

Destaca-se ainda, nesse contexto, que os gestores reafirmam a importância da avaliação institucional como fator de desenvolvimento de uma gestão democrática e participativa, conforme citado anteriormente:

Ela tem uma importância considerável, porque quando os servidores que estão compondo a equipe dentro de uma instituição escolar participam do processo de avaliar os gestores, o corpo diretor consegue ter um feedback e eles se sentem pertencidos a esse processo de construção.

Vejo que a avaliação é importante para que você aperfeiçoe algo que está deixando a desejar, e é muito intuitivo aplicar isso para a gestão.

Não é possível se pensar em uma gestão que se propõe democrática sem avaliar se os resultados do que a gestão está fazendo, ou seja, a ação tem um efeito naquelas pessoas que estão subordinadas aquelas ações.

Um dos entrevistados vê a avaliação institucional como fator formal de desenvolvimento da gestão democrática, pois os participantes percebem o comprometimento da gestão com o processo avaliativo e valorizam esses momentos expondo suas opiniões e formalizando solicitações que não foram atendidas.

Apesar de ter a necessidade de amadurecimento em alguns aspectos, o comprometimento da gestão com a avaliação, com a oportunidade de abrir o acesso para as pessoas falarem $e$ participarem faz com que as falhas sejam mais facilmente superadas e toleradas.

A avaliação institucional da escola é conceituada como um processo que envolve todos os seus atores, buscando negociar patamares adequados de aprimoramento, a começar dos problemas vivenciados por ela (FREITAS et al, 2014). Dessa forma, para que se supere as adversidades que podem distanciar a instituição de uma gestão de fato democrática, indica-se que se destine um tempo maior para discussão dos resultados das avaliações e que os pontos críticos sejam trabalhados individualmente, se for o caso, tendo em vista a superação das dificuldades e o crescimento profissional.

Se a avaliação institucional é proposta com o objetivo de direcionar a ação dos gestores se torna imprescindível que os resultados provenientes dela sejam tratados com rigor e transparência. A comunidade escolar deve sentir-se confiante em relação ao projeto proposto, caso contrário se tornará apenas uma formalidade. 


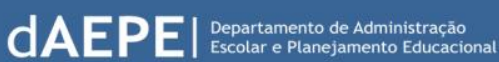

\section{ISSN 2359-82}

A avaliação deve produzir conhecimentos objetivos e constatações acerca de uma realidade. Neste aspecto, a avaliação institucional torna-se um importante instrumento para a melhoria do processo educacional, visto que os dados revelam características dos aspectos avaliados, possibilitando um diagnóstico sobre a instituição de ensino e servindo como base para a tomada de decisões (GROCHOSKA; EYNG, 2005).

Por meio da pesquisa ressalta-se que é imprescindível que os instrumentos da avaliação institucional sejam reformulados de forma participativa, bem como a forma que se direciona os encaminhamentos da avaliação para que reflitam os interesses do coletivo da escola, pois tendo participado da construção, os sujeitos possam se mostrar mais empenhados em avaliar e em serem avaliados.

Aponta-se que os resultados da implementação das ações realizadas a partir da avaliação institucional foram acompanhamento e direcionamento pedagógico, provisionamento de setores, o método de indicação para os coordenadores e diretores intermediários, conversas com os diretores sobre pontos tratados na avaliação, alterações na metodologia das reuniões, feedback para os servidores das ações realizadas com base nas dificuldades apresentadas pelo grupo nas avaliações.

A cultura de avaliação é um projeto a ser construído pelas instituições ao passo que vão inter-relacionando o que são e o que pretendem ser com as ações que continuamente vão planejando, a fim de garantir legitimidade política e validade institucional ao ato avaliativo. Nesse sentido, para que uma instituição desenvolva uma cultura de avaliação é preciso que seja uma ação contínua, constante e democrática (QUEIROZ, 2011).

\section{CONSIDERAÇÕES FINAIS}

A avaliação possui papel relevante na identificação dos fatores que interferem na qualidade, sejam positivos ou não, oferecendo suporte necessário para a tomada de decisão de cunho pedagógico, administrativo ou de políticas institucionais (BELLONI, 1999). Percebe-se que, no âmbito do campus estudado, que a avaliação institucional interna tem sido um fator de direcionamento para diversas ações gestoras, envolvendo aspectos administrativos e pedagógicos, apresentado potencialidades e limitações.

A avaliação institucional realizada no campus teve sua motivação principal na visão de gestão, numa perspectiva democrática, do Diretor Geral que considera relevante a possibilidade 
de ter um acompanhamento do trabalho que está sendo realizado, de verificar se a comunidade escolar se sente bem representada. Verificou-se que como resultado do processo avaliativo que os gestores promovem diversas ações de cunho pedagógico e administrativo.

Os resultados apontam que as ações voltadas à avaliação institucional foram: avaliação de docentes, gestores e setores de atendimento por meio de formulário on-line; formulário online para avaliação dos gestores pelos servidores; reuniões avaliativas com servidores efetivos; formulário para a comunidade registrar sugestões, reclamações e críticas. Por meio da ampliação dos instrumentos avaliativos, nota-se que a gestão busca oportunizar a participação dos diversos segmentos da escola, algo fundamental para a gestão democrática.

Percebe-se ainda, que o processo avaliativo carece de algumas melhorias para que favoreça um desenvolvimento melhor da instituição. Por exemplo, existe certa imaturidade para lidar com os resultados da avaliação institucional, o que pode prejudicar encaminhamentos de ações efetivas. De forma geral, os gestores se ressentem de críticas direcionadas para o campo pessoal. No entanto, a linha que separa pessoal e profissional é sempre tênue.

Dessa forma, é evidente que nem sempre o sentimento de ser avaliado é positivo, se tornando um desafio, principalmente no que se refere ao tratamento dos dados colhidos pela avaliação. É salutar que a equipe perceba suas limitações como algo transitório, já que, por meio desse processo, elas podem ser superadas coletivamente.

Ressalta-se, ainda, que o processo avaliativo carece de algumas melhorias para que favoreça um melhor desenvolvimento da instituição. Desafios sempre serão encontrados em práticas que oportunizam a participação, visto que há uma diversidade de concepções e opiniões acerca da participação no contexto escolar.

Destaca-se que algumas ações podem colaborar efetivamente no aperfeiçoamento da prática de avaliação institucional interna realizada no campus estudado, a saber: reformulação dos instrumentos de avaliação de forma coletiva; metodologia aplicada referendada pela comunidade escolar; o instrumento de avaliação destinado aos docentes poderá incluir um campo para registro de sugestões de melhoria nos setores que os atendem; rigor e transparência no tratamento dos dados levantados pelos questionários e reuniões de avaliação; divulgação da prática de avaliação institucional entre a rede federal.

\section{REFERÊNCIAS}


AFONSO, A. J. Avaliação educacional: regulação e emancipação: para uma sociologia das políticas avaliativas contemporâneas. 3. ed. São Paulo: Cortez, 2005.

BARDIN, Laurence. Análise de conteúdo. (70a Ed.) São Paulo: Almedina, 2016.

BELLONI, I. Avaliação institucional: um instrumento de democratização da educação. Revista Linhas Críticas/Unb. Brasília, v. 5, n. 9, p. 31-58, dez, 1999.

BRASIL. Constituição da República Federativa do Brasil. Diário Oficial da União da República Federativa do Brasil, Brasília, DF, 05 de outubro de 1988. Disponível em:

<http://www.planalto.gov.br/ccivil_03/constituicao/constituicao.htm>. Acesso em: 20 jan. 2018.

Lei no 9.394, de 20 de dezembro de 1996. Estabelece as diretrizes e bases da educação nacional. Brasília, DF, 23 de dezembro de $1996 . \quad$ Disponível em:<http://www.planalto.gov.br/ccivil_03/leis/19394.htm>. Acesso em: 10 mar. 2018.

CASTRO, A. P. Liderança Motivacional: como desenvolver pessoas e organizações, través do coaching e da motivação. Rio de Janeiro: Qualitymark Editora, 2015.

CHIAVENATO. I. Administração nos Novos Tempos. 2 ed. Rio de janeiro: Elsevier, 2004.

CHIAVENATO, I. Gestão de pessoas: o novo papel dos recursos humanos nas organizações. (4a ed.) São Paulo: Manole, 2014.

FERNANDES, M. E. A. Gestão da escola: desafios a enfrentar. Rio de Janeiro: DP\& A, 2002.

FREITAS, L. C. et al. Avaliação educacional: caminhando pela contramão. 6. eed. Rio de Janeiro: Vozes, 2014.

GADOTTI, M. Avaliação institucional: necessidade e condições para a sua realização. 2010. Disponível em: <http://www.paulofreire.org/pub/Institu/SubInstitucional1203023491It003Ps002/Avali_Institucio nal.pdf> Acesso em: 20 de Agosto de 2018.

GIL, A. C. Como elaborar projetos de pesquisa. 5. Ed. São Paulo: Atlas, 2010.

GROCHOSKA, M. A.; EYNG, A. M. A Auto-Avaliação Institucional como Estratégia de Gestão da Escola de Educação Básica. Disponível em: <http://www.pucpr.br/eventos/educere/educere2005/anaisEvento/documentos/com/TCCI142.pdf $>$ Acesso em: 20 de Agosto de 2018.

HADJI, C. Avaliação: as Regras do Jogo. Porto: Porto Editora, 1994.

LIBÂNEO, J. C. et al. Educação Escolar: políticas, estrutura e organização. São Paulo: Cortez, 2012. 


\section{REVISTA DE ADMINISTRAÇÃO EDUCACIONAL}

\section{dAEPE|}

LUCK, H. A gestão participativa na escola. 4. ed. Petrópolis: Vozes, 2008. (Série: Cadernos de Gestão). 2012.

Perspectivas da avaliação institucional da escola. Petrópolis, Rio de Janeiro: Vozes,

QUEIROZ, K. C. A. L. Eu avalio, tu avalias, nós nos autoavaliamos? Uma experiência proposta pelo SINAES. São Paulo: Autores associados, 2011.

SOUSA, S. Z. Avaliação escolar: constatações e perspectivas. Revista de educação, ano 24, n 94, p.59-66, 1995.

VEIGA, I. P. Projeto político-pedagógico da escola: uma construção possível. Campinas: Papirus, 1995. 